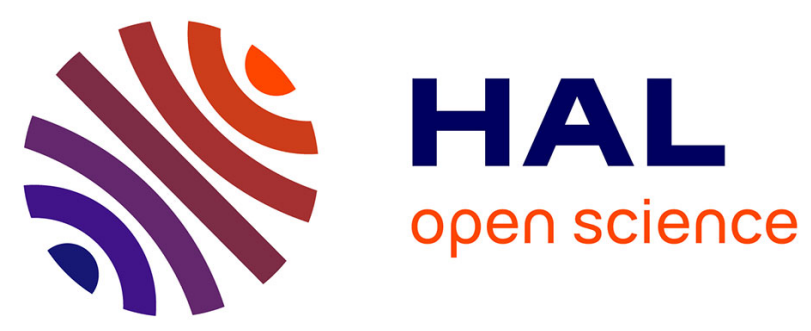

\title{
Alkylthiol self-assembled monolayers on Au(111) with tailored tail groups for attaching gold nanoparticles
}

V y Kutsenko, L Lopatina, Léo Bossard-Giannesini, O Marchenko, Olivier Pluchery, S V Snegir

\section{- To cite this version:}

V y Kutsenko, L Lopatina, Léo Bossard-Giannesini, O Marchenko, Olivier Pluchery, et al.. Alkylthiol self-assembled monolayers on $\mathrm{Au}(111)$ with tailored tail groups for attaching gold nanoparticles. Nanotechnology, 2017, 28 (23), pp.235603 10.1088/1361-6528/aa6e3d . hal-01534253

\section{HAL Id: hal-01534253 \\ https://hal.sorbonne-universite.fr/hal-01534253}

Submitted on 7 Jun 2017

HAL is a multi-disciplinary open access archive for the deposit and dissemination of scientific research documents, whether they are published or not. The documents may come from teaching and research institutions in France or abroad, or from public or private research centers.
L'archive ouverte pluridisciplinaire HAL, est destinée au dépôt et à la diffusion de documents scientifiques de niveau recherche, publiés ou non, émanant des établissements d'enseignement et de recherche français ou étrangers, des laboratoires publics ou privés. 


\title{
Alkylthiol self-assembled monolayers on $\mathrm{Au}(111)$ with
}

\section{tailored tail groups for attaching gold nanoparticles}

\author{
V. Y. Kutsenko ${ }^{I}$, Y. Y. Lopatina ${ }^{I}$, L. Bossard-Giannesini ${ }^{2}$, O. A. Marchenko ${ }^{I}$ O. Pluchery $^{2}$ \\ and S. V. Snegir ${ }^{2,3}$ \\ ${ }^{1}$ Institute of Physics of National academy of sciences of Ukraine \\ Nauky av. 46, Kyiv, 03028, Ukraine \\ ${ }^{2}$ Institut des Nanosciences de Paris, Sorbonne Universités UPMC Univ Paris-06, CNRS- \\ UMR 7588, 4 place Jussieu, 75005 Paris, France \\ ${ }^{3}$ Chuiko Institute of Surface Chemistry of National academy of sciences of Ukraine, Gen. \\ Naumov str.17, Kyiv, 03164, Ukraine
}

\begin{abstract}
Self-Assembled Monolayers (SAM) on $\mathrm{Au}(111)$ are able to control the functionality of a gold surface. We use scanning tunnelling microscopy (STM) in air and contact angle measurements to compare the morphology and the chemistry of three alkylthiol SAMs differing by their tail groups: 1,9-nonanedithiol (NDT) and 1,4-butanedithiol (BDT) and 11mercaptoundecanol (MUOH). STM reveals very different morphologies: hexagonal lattice for MUOH and parallel rows for NDT and BDT. In the case of NDT, we find that the thiol tail groups may form disulfide bridges for long immersion times. The availability of $-\mathrm{SH}$ group for chemical reactions is checked by attaching gold nanoparticles (AuNPs). When the thiol tail group is available, AuNPs readily attach as shown with atomic force microscopy (AFM). When disulfide bridges are formed the gold surface is not able to bind nanoparticles.
\end{abstract}

KEYWORDS: disulfide, dithiol self-assembled monolayer, $\mathrm{Au}(111)$ surface, contact angle, STM, gold nanoparticles.

PACS: 68.08.Bc, 68.08.De 


\section{Introduction}

Alkanethiol molecules have attracted much attention because they form self-assembled monolayers (SAMs) on gold surfaces [25] and other noble metal surfaces [40, 45]. Applications are considered in nanoelectronics [1, 2], sensing [23, 35], catalysis by gold nanoparticles [26, 27] nanoparticle immobilisation [7, 11], adhesion control [14, 46] and in fabrication of nanohybrid architectures [27, 32, 48]. Within this well-organized organic monolayer, the alkanethiol molecules are all parallel, with the $-\mathrm{SH}$ group that forms a covalent bond with the gold surface $\left(\sim 50 \mathrm{kcal} \cdot \mathrm{mol}^{-1}\right)$ [45]. This side is termed the head group, whereas the outward moiety is the tail group. The quality of self-organization processes not only depends on the gold-thiol bond but also on the interaction between the neighbouring alkyls due to lateral van der Waals interaction $\left(\sim 1 \mathrm{kcal} \cdot \mathrm{mol}^{-1}\right.$ per $-\mathrm{CH}_{2}-$ group $)[8,42]$. The increase of alkyl chain length leads to its tilting within a SAM instead of standing upright $[21,25,36,41]$ or in some cases to laying phase [8] even when concentration is sufficient to form dense packing. This tilting appears since molecules optimize the intermolecular interaction and balance the head group-substrate interaction, thus minimizing the surface energy. Typical alkanethiol molecules within SAMs may have an orientation with an average tilt angle of $\sim 27^{\circ}-35^{\circ}$ with respect to the surface normal $[10,16,30]$. Such structures are achieved when concentration of 10-1000 mM are used [45]. For lower concentrations, alkanethiol may adopt a flat-laying orientation arranged along rows on the surface forming the so-called "stripe phase" [45].

The tail group that points outward the surface can have different chemical compositions which define the chemical and physical properties of the functionalized surface. For example, $\mathrm{CH}_{3}$ and $-\mathrm{CF}_{3}$ as tail groups make the SAM surface hydrophobic, metallophobic and highly anti-adherent,[36], while $-\mathrm{COOH},-\mathrm{NH}_{2}$ or $-\mathrm{OH}$ tail groups yield hydrophilic surfaces with good metal ion and protein binding properties [3, 25, 45]. Among tail groups a very popular one is the $-S H$ (thiol) end-group since it allows attaching various nanoobjects (noble metal 
nanoparticles, nanorods, etc) to a gold substrate or cross-link them between each other $[5,6,18$, $27,32,34,48]$. To that end, dithiol molecules are of particular interest because they can be used for attaching gold nanoparticles (AuNPs). However the sulfur-metal interfacial chemistry remains a controversial topic[45]. It was found that for a given dithiol, changes of the concentration and deposition conditions may lead to lying phase [22], loops or standing phase on the gold surface, the latter being called "brush-like" structure [45]. Elaborated methods of $\mathrm{Au}(111)$ functionaliziation were proposed, for AuNPs immobilization to gold via an hexanedithiol linker for example [28].

In the present paper, we compare three SAMs on $\mathrm{Au}(111)$ with different tail groups $(-S H$ and $-\mathrm{OH}$ ) and different chain lengths. The capacity of forming ordered monolayers is probed by STM and correlated to their chemical properties by contact angle measurements. In the case of dithiol-based SAMs, we compare how the nature of the tail groups leads to the immobilization of AuNPs. We show that in certain conditions long alkyl chains may lead to the formation of disulfide groups that cannot retain AuNPs. We also establish a procedure for avoiding or minimizing this disulfide formation.

\section{Methods}

Sample preparation. The $\mathrm{Au}(111)$ substrates are thin gold layers evaporated on mica purchased from Phasis (Switzerland). Before deposition, atomically-flat terraces were prepared by annealing in a propane-butane flame $\left(\sim 50^{\circ} \mathrm{C}-150^{\circ} \mathrm{C}\right.$ for $90 \mathrm{sec}$, then at $\sim 350^{\circ} \mathrm{C}, 2-3$ sec). STM images of the resulting substrate reveal the well-known herringbone reconstruction pattern of $\mathrm{Au}(111)$ (figure 1-a) as an evidence of the chemical purity of the surface before molecules deposition [32]. As it is well known the herringbone structure is made of alternative hcp and fcc domains [17]. 
a)

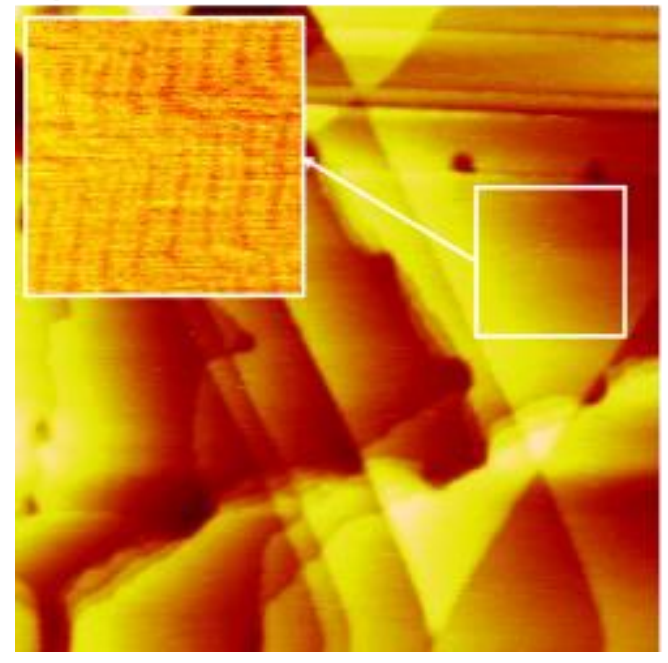

b)

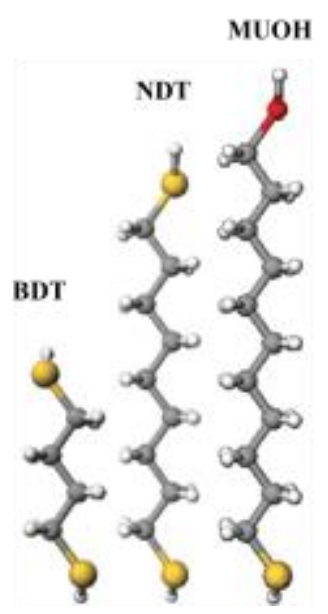

Figure 1. (a) STM images $\left(300 \times 300 \mathrm{~nm}^{2}\right)$ of clean $\mathrm{Au}(111)$ surface after flaming. The inset shows the zigzag stripes of the reconstructed herringbone structure of gold. (b) Chemical structures of butanedithiol (BDT), nonanedithiol (NDT) and mercaptoundecanol (MUOH)

Three different SAMs were prepared with butanedithiol (BDT), nonanedithiol (NDT) and mercaptoundecanol (MUOH) dissolved in ethanol with a concentration $1.5 \times 10^{-3}$ mol. $\mathrm{L}^{-1}$ (figure 1-b). The freshly annealed gold surfaces were immersed in these ethanolic solutions for either $30 \mathrm{~s}$ (process \#1) or $40 \mathrm{~min}$ (process \#2) at ambient conditions. In order to remove the excess of physisorbed molecules, the substrates were rinsed in pure ethanol (HPLC-grade) and dried in nitrogen flow. All chemicals were purchased from Sigma-Aldrich and used as received.

The synthesis of gold nanoparticles was achieved following the Turkevich-Frens method $[13,20]$. An aqueous solution of $\mathrm{HAuCl}_{4}\left(2.5 \times 10^{-4}\right.$ mol.L-1 $)$ was heated up to boiling in an Erlenmeyer flask. Then $1 \mathrm{~mL}$ of an aqueous sodium citrate solution $\left(1.7 \times 10^{-2}\right.$ mol. $\left.\mathrm{L}^{-1}\right)$ was added under vigorous stirring. When AuNPs are formed, the solution has a clear ruby-red colour. It was stored at $4^{\circ} \mathrm{C}$ to avoid nanoparticle aggregation.

In the case of the dithiol solutions of NDT and BDT, the gold substrates were immersed in the aqueous AuNPs suspension for 1 hour. We checked visually that no aggregation occurred 
upon deposition: the few colloidal solutions that turned blue were discarded. The resulting substrates with AuNPs were finally rinsed several times with ultrapure water and dried in a nitrogen flow.

The structure of monolayers on $\mathrm{Au}(111)$ surface was investigated using a commercial STM (NT-MDT, Russia). STM tips were mechanically cut from a $0.25 \mathrm{~mm}$ Pt/Ir (80:20) wire. The calibration of STM piezoelements was checked by imaging the structure of SAM of MUOH on $\mathrm{Au}(111)$ and distances are measured with an accuracy of $0.05 \mathrm{~nm}$. All STM-images were recorded in the constant-current mode. The STM tunnelling parameters typically used in our experiments were 0.1-1.0 $\mathrm{V}$ and $0.2-0.5 \mathrm{nA}$.

The AFM characterizations of AuNPs attachment was performed by a Bruker Multimode apparatus operating in the PeakForce ${ }^{\circledR}$ mode. STM and AFM measurements were carried out at ambient conditions.

The measurements of contact angle at solid-liquid-gas interface were performed immediately after substrate functionalization and its drying. The volume of the deposited droplets was equivalent to $3 \mu 1$. The contact angle measurements were performed by custom-made apparatus (Institute of Physics NAS of Ukraine) with software Micro-Measure version 1.2. (license GNU). The results were processed using ImageJ. Each time, a minimum of five measurements were carried out and the error was below $\pm 2^{\circ}$ (details in the Supplementary data). The calibration was achieved by measurements of contact angles at water-vapor interface for bare graphite and $\mathrm{Au}(111)$ surfaces in comparison with the values obtained by commercially manufactured equipment [42].

\section{Results}

The STM images of the three different SAMs prepared following process \#2 reveal periodic structures with either bright spots in the case of MUOH (figure 2-a) or rows in the case of BDT and NDT (figure 3). All these structures exhibit randomly distributed large dark spots (pits) 
which are known features for such surfaces [44]. The depth of these pits is a multiple of the height of a monoatomic gold step $(2.4 \AA)$, and they are a consequence of the strong interaction between $-S H$ groups and gold atoms at the $\mathrm{Au}(111)$ surface: alkythiol molecules strongly modify the initial surface reconstruction and pull out gold atoms during self-assembling [44]. Such behaviour occurs with every SAM studied in this work. On a smaller scale, the STM contrasts depends on the nature of the tail groups $(-\mathrm{OH}$ and $-\mathrm{SH})$ and the length of the alkyl chains $\left(-\left[\mathrm{CH}_{2}\right]_{n}-, \mathrm{n}=11,9,4\right)$, as shown in the insets of figures 2 and 3. For $\mathrm{MUOH}$, the bright spots are arranged into a hexagonal structure $(\sqrt{3} \times \sqrt{3}) R 30^{\circ}$ and the lateral distance between the neighbouring spots is equal to $5 \pm 0.3 \AA$.

a)

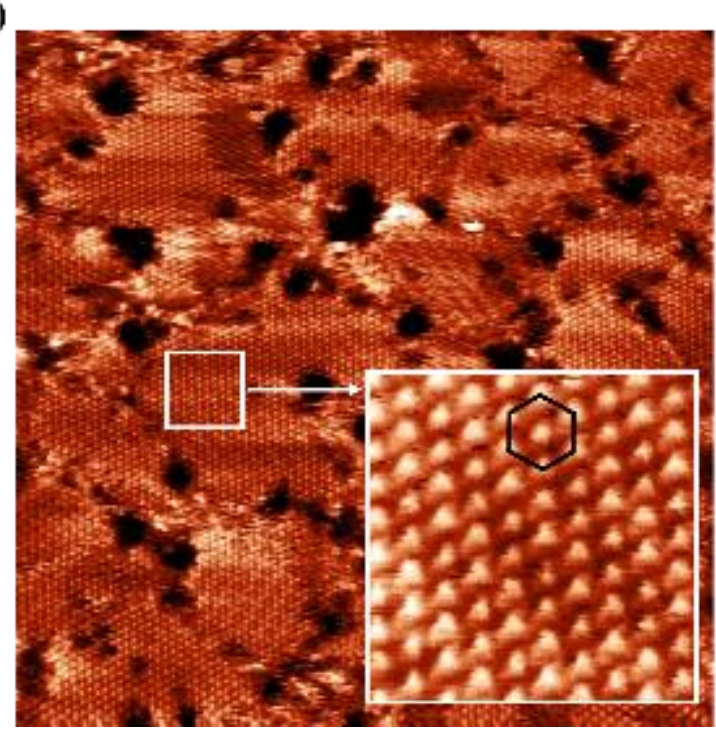

b)

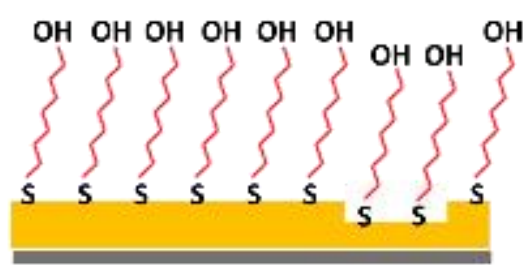

c)

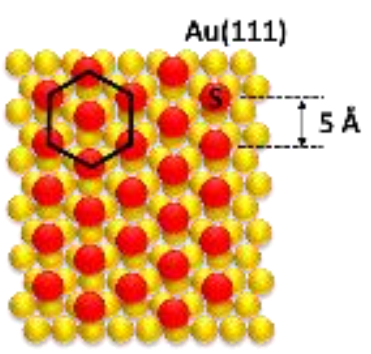

Figure 2. STM images $\left(45 \times 45 \mathrm{~nm}^{2}\right)$ of (a) hexagonally packed SAM of MUOH. Each bright spot of the inset $\left(4.3 \times 4.3 \mathrm{~nm}^{2}\right)$ corresponds to terminal $-\mathrm{OH}$ tail groups. The distance between the spots is $5 \AA$ A. (b) Schematic models for the packing of thiols on a gold surface: "brush-like structure" (side view); (c) hexagonal $(\sqrt{3} \times \sqrt{ } 3) R 30^{\circ}$ structure (top view). The red disks indicate the positions of the sulfur atom bound in the three-fold hollow sites of the gold.

For NDT, the SAM is organized into parallel rows separated from each other by $15 \AA$. When several domains are observed, an angle of $60^{\circ}$ is found between the orientation of rows which 
suggests an epitaxial relationship between SAM and the underlying $\mathrm{Au}(111)$ substrate. The variation of scanning directions, as well as STM-tunnelling parameters did not influence the angle between molecular rows and single bright spots were never observed with NDT SAM. Interestingly, when the NDT-SAM is prepared with a short immersion time following procees\#1, the image displays irregular domains and is hardly observable with STM (see SI, Fig. S1). STM images of BDT SAM prepared according to process \#2 reveals domains with a similar row-like structure as for NDT. The lateral distance between rows is also equal to $15 \AA$ (figure 3). However, the ordered domains cover just $70 \%$ of the surface with BDT whereas they represent $95 \%$ with NDT.

a)

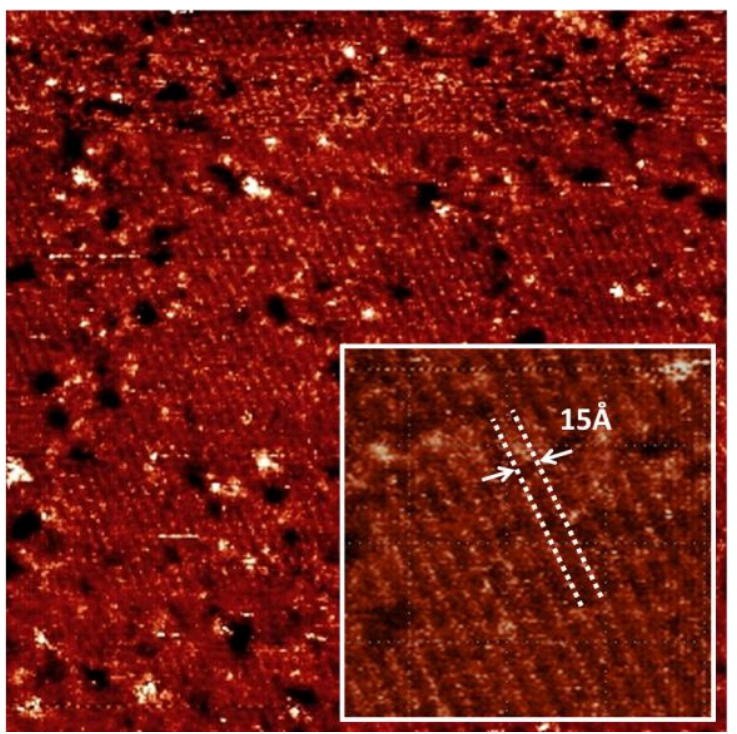

b)

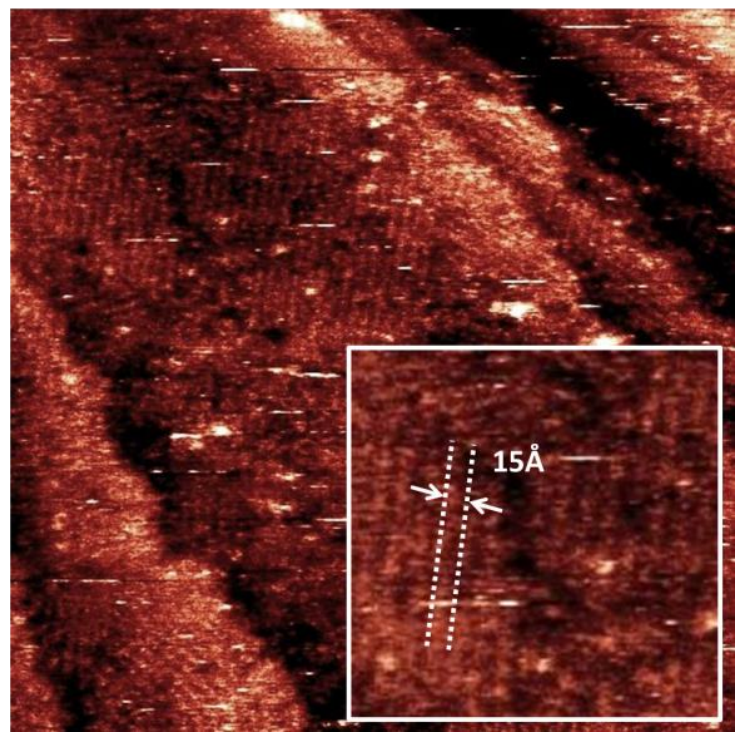

Figure 3. STM images $\left(90 \times 90 \mathrm{~nm}^{2}\right)$ of the SAMs formed on $\mathrm{Au}(111)$ with (a) NDT and (b)

BDT. Row-like structures appear due to the formation of disulfide between neighbour $-S H$ tail groups (see text). The immersion time of $\mathrm{Au}(111)$ in the corresponding solutions of NDT and BDT was 40 min.

Wetting properties of the surface. The contact angles measurements at the droplet-gold interface gives a value of $66^{\circ}$ in the case of a freshly annealed gold surface (figure 4-a) which is 
indicative of gold atoms in a reduced state [38]. For MUOH, BDT and NDT, the contact angles were found to be equal to $22^{\circ}$ (not presented), $47^{\circ}$ and $68^{\circ}$ respectively (figure- $4 \mathrm{~b}, \mathrm{c}$ ). This is consistent with a hydrophilic surface in the case of $\mathrm{MUOH}$ and a more hydrophobic surface with BDT and NDT. One would expect that these two SAMs have the same contact angles, since both molecules have the same $-S H$ terminal groups pointing outwards the surface. This will be addressed below. Moreover if the gold substrate is immersed in NDT for 40 min (instead of $30 \mathrm{sec}$ ) the contact angle rises from $68 \pm 0.4^{\circ}$ to $74 \pm 0.5^{\circ}$. For BDT the surface also becomes more hydrophobic with an increase of the contact angle by at least $14^{\circ}$. A complete set of contact angles values of BDT, NDT and for different samples is given in the Supplementary Data (see Table S1).

a)

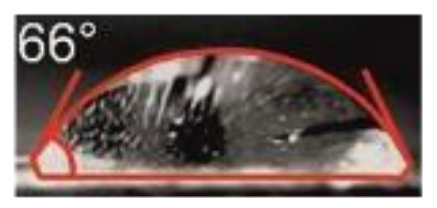

c)

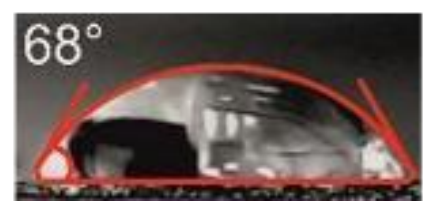

b)

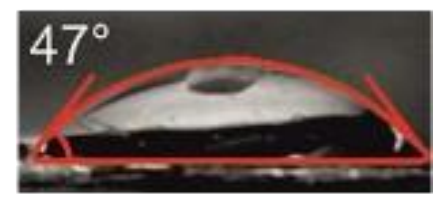

d)

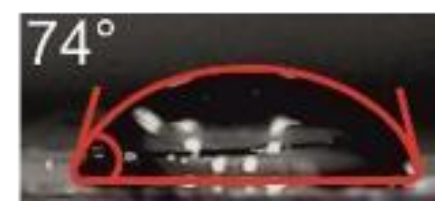

Figure 4. Optical microscope images of an ultrapure water droplet on various SAMs along with the values of the corresponding contact angles for (a) annealed gold, (b) BDT for $30 \mathrm{sec}$, (c) NDT for $30 \mathrm{sec}$ and (d) NDT for $40 \mathrm{~min}$.

AFM measurements were performed after deposition of AuNPs on NDT SAM in two cases: on $\mathrm{Au}(111)$ exposed to NDT for $30 \mathrm{sec}$ and on $\mathrm{Au}(111)$ exposed to NDT for $40 \mathrm{~min}$. AFM revealed drastic differences. The substrate exposed to NDT for $30 \mathrm{sec}$ (process \#1) was covered by a large number of spots: $\sim 350$ spots $/ \mu \mathrm{m}^{2}\left(540\right.$ and $600 \mathrm{spots} / \mu \mathrm{m}^{2}$ for two other experiments, not shown). The profile analysis in figure 5 -a, shows that the height of each spot is 
$17 \pm 1 \mathrm{~nm}$ which matches with the expected size of AuNPs from the colloidal solution [39]. These spots can be unambiguously assigned to the AuNPs, which are known to be spherical. The lateral size of the spots is $30 \mathrm{~nm}$ (figure 5-a, inset) is slightly larger than the actual particle diameter due to the convolution with the AFM tip. Particles were never displaced on the surface during AFM measurements. This suggests that AuNPs are strongly anchored to the surface by NDT. The analysis of different areas also revealed a homogeneous coating of the surface by AuNPs in spite of the presence of flat $\mathrm{Au}(111)$ terraces and gold steps edges. It means that $\mathrm{Au}(111)$ surface is covered entirely by NDT molecules. No preferred adsorption positions of AuNPs were found. The surface density of AuNPs is relatively low (350 AuNPs/ $/ \mathrm{m}^{2}$ ). They cover about $15 \%$ of accessible gold surface. A longer immersion time of NDT-covered substrates into AuNPs colloidal solution leads to an increase of AuNPs coverage. In the case of the longer functionalization time in NDT (process \#2, 40 min) and same immersion time in colloidal AuNPs $(1 \mathrm{~h})$ the AFM images display consistently less than 10 AuNPs $/ \mu m^{2}$. In figure 5-b a surface density of $8 \mathrm{AuNPs} / \mu \mathrm{m}^{2}$ is counted. The AuNPs are mainly trapped by defects like step edges, while the probability of trapping by atomically flat terraces seems much lower.

a)

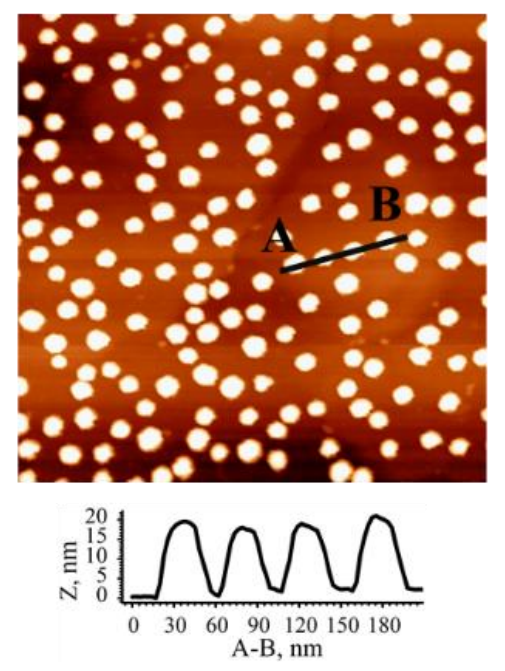

b)

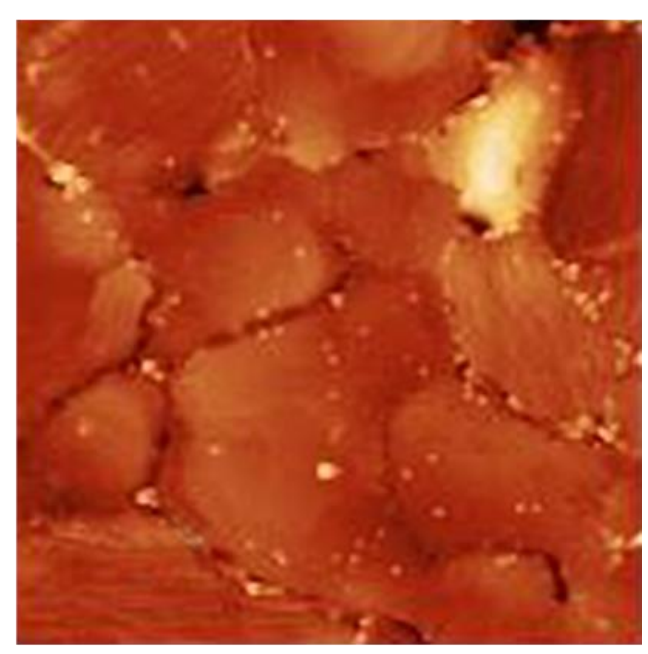


Figure 5. AFM images of AuNPs after immobilization by the $-S H$ tail groups of the NDT SAM. (a) $0.7 \times 0.7 \mu \mathrm{m}^{2}$ area with high coverage of AuNPs in the case of short immersion into NDT solution ( $30 \mathrm{sec}$ ); the inset is a cross section along line $\mathrm{AB}$; (b) $3 \times 3 \mu \mathrm{m}^{2}$ area after $40 \mathrm{~min}$ immersion into NDT showing very few AuNPs attachment.

\section{Discussion}

STM shows that MUOH SAMs form a hexagonal lattice where the average distance between the bright spots is of $5 \pm 0.5 \AA$. The average occupancy for one spot is $0.23 \mathrm{~nm}^{2}$ (calculated from figure 2-a). In the case of adsorption of alkanethiol into a $(\sqrt{ } 3 \times \sqrt{ } 3) R 30^{\circ}$ structure, each molecule is known to occupy an average area per molecule of $0.216 \mathrm{~nm}^{2}$ which is consistent with our value[22] [24]. Each spot represents the position of one $-\mathrm{OH}$ terminal group of the MUOH molecule (see figure 2-b) and form the "brush-like structure" [33]. Each sulfur atom is bound equivalently to the $\mathrm{Au}(111)$ lattice on a hollow site (Figure 2-c). The $\mathrm{OH}$ moiety points outwards the surface and explains the hydrophilic character of the surface (contact angle of $22^{\circ}$ ). This MUOH SAM serves as a reference when assessing the surface properties of NDT and BDT SAMs. For these two latter SAMs the adsorption configuration of the head group onto $\mathrm{Au}(111)$ surface remains the same, bonding in the three-fold hollow site, while the tail group may form a different structure.

In the case of NDT and BDT, as shown in figure 3, the SAM has a row-like structure with lateral distances of $\sim 15 \AA$ when prepared with process\#2. At that point, it is important to first discuss the possible adsorption geometries. Dithiol molecules can in principle binds to gold through both terminal sulfur atoms so that the molecule would anchor to two points on the surface. Such examples are reported for hexanedithiol [22], benzenedithiol [19] on Au(111) and octanedithiol on $\operatorname{Ag}(111)[4]$. Given that sulfur adsorbs on the three-fold hollow site of $\mathrm{Au}(111)$, this double end adsorption results into a back-folded geometry where the molecule forms a bridge over the surface. If we consider the possibility of a back-folded geometry for NDT (total 
length of a free molecule is $13.69 \AA$ ) and if we assume that this also leads to a self-organization into rows, we found that the inter-row distance would be $11.4 \AA$. This estimation is based on force field optimization with ChemSketch ${ }^{\circledR}$ software and is explained in the Supplementary Data (see Fig. S2). This value is significantly smaller than the $15 \AA$ obtained from the STM measurement. For BDT, the free molecule has a length of $7.13 \AA$ and the back-folded geometry would result in even narrower stripes. This tends to rule out the back-folded geometry. If now we assume another possibility where NDT and BDT interact with the surface through the lateral alkyl groups with Van der Waals interaction, the molecules would be completely stretched and lie flat. Under these conditions the stripes would reach a period of $13 \AA$ for BDT and $20 \AA$ for NDT. This is not compatible with STM observation since in both cases the period is identical. Moreover, if the molecule was in a flat-lying phase, no thiol bond would be available for attaching AuNPs as well as in a case of back-folding phase, and the situation depicted in Fig. 5a would not have been observed. Therefore, this is very unlikely that NDT and BDT adopt this flat lying geometry.

In a detailed study, Daza Millone and co-authors have shown by XPS that NDT prepared in ethanol with $24 \mathrm{~h}$ immersing forms preferentially a standing-up phase.[9] They reach this conclusion by measuring the ratio of the $\mathrm{S} 2 \mathrm{p}$ core level shift at $163.5 \mathrm{eV}$ related to free $\mathrm{S}-\mathrm{H}$ bonds or disulfides and $162 \mathrm{eV}$ related to thiolates. Interestingly, by monitoring the $163.5 \mathrm{eV}$ peak, they conclude that the signal comes from terminal sulfur atoms that have formed disulfide bridges. Their experimental conditions correspond to our process\#2. Therefore it indicates that BDT and NDT adopt a standing-up geometry.

The explanation of this striped-phase can be found by comparing process\#1 and process\#2. When the NDT SAM is prepared according to process\#1, the domains with parallel rows appear to be much smaller (self-organized area of $10 \times 10 \mathrm{~nm}^{2}$ ) and the surface is poorly organized as shown in Figure S1 (Supplementary Data). The formation of the parallel lines is a relatively slow process that occurs inside the NDT solution. Moreover the value of $15 \AA$ matches well 
with the distance between paired rows and can be explained by a pairing of molecules. Actually at ambient conditions the oxidation of two $-\mathrm{SH}$ groups leads to the formation of disulfide as shown in Figure $6[29,43]$. The observation of straight rows over large distances $(\sim 50 \mathrm{~nm})$ as shown in Fig. 3-a suggests a self-organization process which starts from the moment of association of the first two molecules (discussed below) and supposes a strong surface reorganization. It was not possible to observe with STM the in-situ transition of a SAM from single $-S H$ groups, to double row. It suggests that the NDT SAM undergoes this transition in solution. The transition was only measured with contact angle technique.

In the case of BDT, the smaller proportion of striped domains (70\% of the area) observed after 40 min dipping time indicates that the disulfide formation is not as likely to be formed and that the surface still contains unoxidized $-S H$ groups. In a previous study, it has been shown that BDT SAM formation leads to a mix of standing-up and flat-lying phases, contrary to NDT which leads to disulfides formation.[9] And thus, the disulfides formation is lower for BDT compare to NDT. This weaker tendency of BDT for forming rows can be explained by the shorter chain length and by the weaker van der Waals interactions between the alkyl chains in neighbouring molecules [33]. Such difference appeared due to (i) a stronger lateral interaction between $-\left[\mathrm{CH}_{2}\right]-$ units of alkyl chains of NDT $\left(\sim 5 \mathrm{k} . c \mathrm{l} . \mathrm{mol}^{-1}\right)$ [42] and (ii) an increase of the steric effects confining the accessible range of tilt angles, for NDT during the process of the self-organization [42]. Notice that the concentration of the molecules during SAM formation was equivalent for both molecules. Therefore, concentration should probably have no influence on the ordering of the SAMs [25]. At the same time the more rigid structure of BDT will oppose the disulfide formation. 
a)

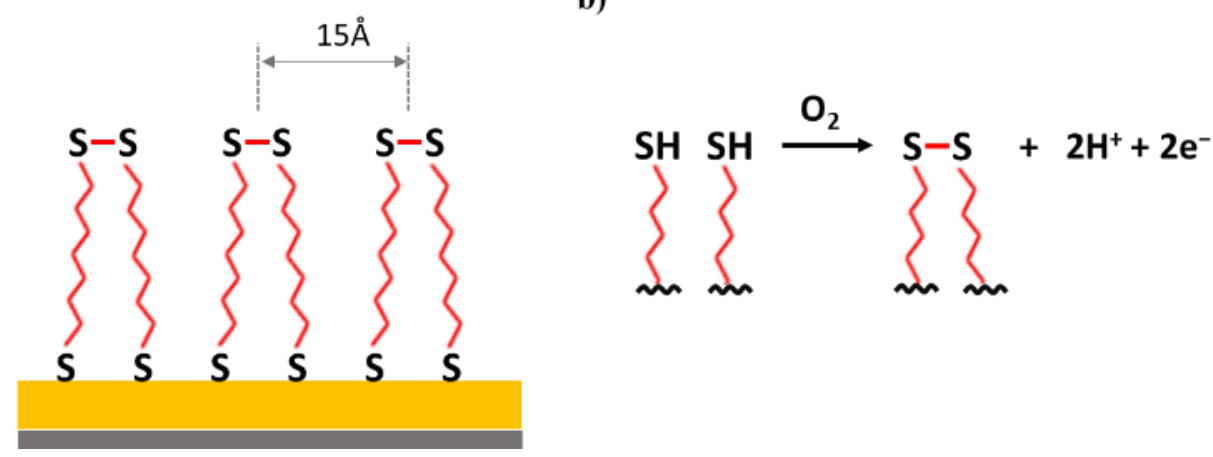

Figure 6. (a) Schematic model of the double row structure of dithiol molecules on Au(111) surface and (b) scheme of the oxidation of thiol $(-\mathrm{SH})$ tail groups of alkyldithiols in presence of oxygen that result into disulfide.

This row-like surface of NDT turns out to be rather hydrophobic (contact angle of $68 \pm 0.4^{\circ}$ ) which is consistent with a $-S H$ terminated surface. Interestingly when the reaction time of NDT with $\mathrm{Au}(111)$ is increased from $30 \mathrm{sec}$ to $40 \mathrm{~min}$, the surface becomes more hydrophobic (contact angle of $74 \pm 0.5^{\circ}$, see Table S1 in the Supplementary Data). This slight contact angle increase is below the error bars and is consistent with the progression of the disulfide formation since the $-S-S$ - moiety is expected to be hydrophobic (non-polar bond). A short reaction time of NDT leads to a less disulfide and more available $-S H$ tail groups.

The NDT SAM is made of vertically oriented molecules which are densely packed. This monolayer has few defects. Therefore, the resulted contact angle is defined by the interaction of water and the thiol tail groups of NDT. When the alkyl chain length is shorter such as the case of BDT, the self-organization of the molecules into parallel vertical units is less favoured due to the weakening of van der Waals interaction between the short alkyl chains. Therefore the surface is only partially covered by domains with vertically oriented molecules. The residual surface is made of disordered domains, where the molecules could even adopt a low-coverage molecular phase with a horizontal orientation [33]. Therefore, the contact angle is not only defined by the interaction of water with the thiol tail groups but also with the hydrophobic 
methylene groups of the alkyl chain. A similar impact of the methylene groups on the contact angle was observed for mixed SAMs formed by long alkyl chains which are partially folding on a vertically oriented short alkyl chains [12].

This formation of the disulfide can be used for controlling the attachment of AuNPs on the NDT SAM. The activation of such chemical reaction occurs in the presence of oxygen [47] and plays a critical role in biochemistry because it prevents the folding of some proteins and their oxidation [37]. The reaction of two terminal $-S H$ groups of neighbouring rows causes the formation of disulfide $-S-S-$ covalent bonds. AuNPs are known to bind to the SAM through the terminal SH groups. Disulfide can also bind to gold [15, 25, 31] but with a lower affinity. Navarro et al. studied the binding of disulfide on gold nanoparticles and concluded that the bond was weaker than with planar gold. The AFM results support this assumption. When process \#1 is used for preparing the NDT SAM, AuNPs can bind to the SAM and a surface coverage of $350 \mathrm{AuNPs} / \mu \mathrm{m}^{2}$ is observed after $1 \mathrm{~h}$ immersion time. However, when process \#2 is used, disulfide is formed over the entire surface and AuNPs can hardly bind. A coverage of only $8 \mathrm{AuNPs} / \mu \mathrm{m}^{2}$ is measured. For intermediate immersion time, an intermediate coverage is obtained (see Fig. S3). This low affinity of disulfide for attaching AuNPs can be used as a practical way for controlling the surface coverage of AuNPs on a SAM.

\section{Conclusions}

In summary, we have studied the formation of three SAMs on Au(111) with MUOH, BDT and NDT. MUOH is found to form a $(\sqrt{3} \times \sqrt{ } 3) R 30^{\circ}$ structure which is highly hydrophilic. For NDT and BDT, the terminal $-S H$ groups oxidized and create disulfide by pairing two neighbouring molecules and form rows spaced with $\sim 15 \AA$. With short-chain BDT this process is limited to small domains whereas with NDT the formation of large row-like domains is enabled. A kinetic mechanism is also unravelled for NDT so that a short immersion (30 sec) in NDT will limit the formation of disulfide bridges and preserve $-S H$ tail groups. This property is 
used for controlling the attachment of gold nanoparticles. When $-S H$ tail groups are available AuNPs can be attached whereas this attachment process is blocked when these groups react into disulfide. In the case of a NDT SAM prepared with a short immersion time (30 sec) we could deposit an amount of $500 \mathrm{AuNPs} / \mu \mathrm{m}^{2}$.

\section{Acknowledgements}

SVS and OP acknowledge the support of the Ministry of Education and Science of Ukraine and the Ministry for Foreign Affairs in France (project DNIPRO 2015-2016, N 34846NB). YYL is grateful to the Marie Curie FP7 ILSES project (ID 612620) for funding her stay at INSP. This work was also supported by the Region Ile-de-France in the framework of DIM Nano-K (PME 2014 program).

\section{References}

[1] Akkerman H B and de Boer B 2008 Electrical conduction through single molecules and self-assembled monolayers J. Phys. Condens. Matt. 20

[2] Bose S K, Lawrence C P, LiuZ, Makarenko K S, van Damme R M J, Broersma H J and van der Wiel W G 2015 Evolution of a designless nanoparticle network into reconfigurable Boolean logic Nat Nano 10 1048-52

[3] Burshtain D and Mandler D 2006 The effect of surface attachment on ligand binding: studying the association of $\mathrm{Mg} 2+, \mathrm{Ca} 2+$ and $\mathrm{Sr} 2+$ by 1 -thioglycerol and 1,4-dithiothreitol monolayers Phys. Chem. Chem. Phys. 8 158-64

[4] Cavallini M, Bracali M, Aloisi G and Guidelli R 1999 Electrochemical STM Investigation of 1,8-Octanedithiol Self-Assembled Monolayers on $\mathrm{Ag}(111)$ in Aqueous Solution Langmuir $153003-6$

[5] Cha H, Yoon J H and Yoon S 2014 Probing Quantum Plasmon Coupling Using Gold Nanoparticle Dimers with Tunable Interparticle Distances Down to the Subnanometer Range ACS Nano 8 8554-63

[6] Chen J, Miao Y and Wu X 2007 Immobilization of Prussian blue nanoparticles onto thiol SAM modified Au electrodes for analysis of DL-homocysteine Colloid Journal 69 660-5

[7] Cichomski M, Tomaszewska E, Kosla K, Kozlowski W, Kowalczyk P J and Grobelny J 2011 Study of dithiol monolayer as the interface for controlled deposition of gold nanoparticles Materials Characterization 62 268-74

[8] Creczynski-Pasa T B, Millone M A D, Munford M L, de Lima V R, Vieira T O, Benitez G A, Pasa A A, Salvarezza R C and Vela M E 2009 Self-assembled dithiothreitol on Au surfaces for biological applications: phospholipid bilayer formation Phys. Chem. Chem. Phys. 11 1077-84

[9] Daza Millone M A, Hamoudi H, Rodriguez L, Rubert A, Benitez G A, Vela M E, Salvarezza R C, Gayone J E, Sanchez E A, Grizzi O, Dablemont C and Esaulov V A 
2009 Self-Assembly of Alkanedithiols on Au(111) from Solution: Effect of Chain Length and Self-Assembly Conditions Langmuir 25 12945-53

[10] Fenter P, Eisenberger $P$ and Liang K S 1993 Chain-length dependence of the structures and phases of $\mathrm{CH} 3-(\mathrm{CH} 2) n-S H$ self-assembled on $\mathrm{Au}(111)$ Physical Review Letters 70 2447-50

[11] Ferreira V C, Silva A F and Abrantes L M 2010 Electrochemical and Morphological Characterization of New Architectures Containing Self-Assembled Mono layers and AuNPs J. Phys. Chem C 114 7710-6

[12] Folkers J P, Laibinis P E and Whitesides G M 1992 SELF-ASSEMBLED MONOLAYERS OF ALKANETHIOLS ON GOLD - THE ADSORPTION AND WETTING PROPERTIES OF MONOLAYERS DERIVED FROM 2 COMPONENTS WITH ALKANE CHAINS OF DIFFERENT LENGTHS Journal of Adhesion Science and Technology 6 1397-410

[13] Frens G 1973 Controlled Nucleation for Regulation of Particle-Size in Monodisperse Gold Suspensions Nature-Physical Science 241 20-2

[14] Gojzewski H, Kappl M, Butt H-J and Ptak A 2016 Influence of Temperature on the Nanoadhesion of a Methyl-Terminated Thiol Monolayer: A New Insight with High-Rate Dynamic Force Spectroscopy Langmuir 32 4500-8

[15] Gronbeck H, Curioni A and Andreoni W 2000 Thiols and disulfides on the $\mathrm{Au}(111)$ surface: The headgroup-gold interaction J. Amer. Chem. Soc. 122 3839-42

[16] Hähner G, Kinzler M, Thümmler C, Wöll C and Grunze M 1992 Structure of selforganizing organic films: A near edge $\mathrm{x}$-ray absorption fine structure investigation of thiol layers adsorbed on gold Journal of Vacuum Science \& Technology A 10 2758-63

[17] Hanke F and Bjork J 2013 Structure and local reactivity of the Au(111) surface reconstruction Physical Review $B \mathbf{8 7}$

[18] Jafri S H M, Lofas H, Blom T, Wallner A, Grigoriev A, Ahuja R, Ottosson H and Leifer K 2015 Nano-fabrication of molecular electronic junctions by targeted modification of metalmolecule bonds Scientific Reports 5

[19] Kestell J, Abuflaha R, Garvey M and Tysoe W T 2015 Self-Assembled Oligomeric Structures from 1,4-Benzenedithiol on $\mathrm{Au}(111)$ and the Formation of Conductive Linkers between Gold Nanoparticles J. Phys. Chem C 119 23042-51

[20] Kimling J, Maier M, Okenve B, Kotaidis V, Ballot H and Plech A 2006 Turkevich Method for Gold Nanoparticle Synthesis Revisited J. Phys. Chem. B 110 15700-7

[21] Laibinis P E, Whitesides G M, Allara D L, Tao Y T, Parikh A N and Nuzzo R G 1991 Comparison of the structures and wetting properties of self-assembled monolayers of $n$ alkanethiols on the coinage metal surfaces, copper, silver, and gold J. Amer. Chem. Soc. $1137152-67$

[22] Leung T Y B, Gerstenberg M C, Lavrich D J, Scoles G, Schreiber F and Poirier G E 2000 1,6-Hexanedithiol Monolayers on Au(111): A Multitechnique Structural Study Langmuir $16549-61$

[23] Lioubashevski O, Chegel V I, Patolsky F, Katz E and Willner I 2004 Enzyme-catalyzed bio-pumping of electrons into Au-nanoparticles: A surface plasmon resonance and electrochemical study J. Amer. Chem. Soc. 126 7133-43

[24] Liu Y F, Yang Y C and Lee Y L 2008 Assembly behavior and monolayer characteristics of $\mathrm{OH}$-terminated alkanethiol on $\mathrm{Au}(111)$ : in situ scanning tunneling microscopy and electrochemical studies Nanotechnology 19

[25] Love J C, Estroff L A, Kriebel J K, Nuzzo R G and Whitesides G M 2005 Self-assembled monolayers of thiolates on metals as a form of nanotechnology Chem. Rev. 105 1103-69

[26] Mancin F, Prins L J and Scrimin P 2013 Catalysis on gold-nanoparticle-passivating monolayers Current Opinion in Colloid \& Interface Science 18 61-9 
[27] Maye M M, Luo J, Lin Y H, Engelhard M H, Hepel M and Zhong C J 2003 X-ray photoelectron spectroscopic study of the activation of molecularly-linked gold nanoparticle catalysts Langmuir 19 125-31

[28] Morel A L, Volmant R M, Methivier C, Krafft J M, Boujday S and Pradier C M 2010 Optimized immobilization of gold nanoparticles on planar surfaces through alkyldithiols and their use to build 3D biosensors Colloids and surfaces. B. Biointerfaces 81 304-12

[29] Nagy P 2013 Kinetics and Mechanisms of Thiol-Disulfide Exchange Covering Direct Substitution and Thiol Oxidation-Mediated Pathways Antioxidants \& Redox Signaling 18 1623-41

[30] Nuzzo R G, Dubois L H and Allara D L 1990 Fundamental studies of microscopic wetting on organic surfaces. 1. Formation and structural characterization of a self-consistent series of polyfunctional organic monolayers J. Amer. Chem. Soc. 112 558-69

[31] Nuzzo R G, Fusco F A and Allara D L 1987 Spontaneously organized molecular assemblies. 3. Preparation and properties of solution adsorbed monolayers of organic disulfides on gold surfaces J. Amer. Chem. Soc. 109 2358-68

[32] Olichwer N, Leib E W, Halfar A H, Petrov A and Vossmeyer T 2012 Cross-Linked Gold Nanoparticles on Polyethylene: Resistive Responses to Tensile Strain and Vapors ACS Applied Materials \& Interfaces 4 6151-61

[33] Poirier G E 1997 Characterization of organosulfur molecular monolayers on Au(111) using scanning tunneling microscopy Chem. Rev. 97 1117-27

[34] Rajendra $R$ and Ballav N 2013 Discriminative response of aliphatic and aromatic dithiol in the self-assembly of gold nanoparticles RSC Advances 3 15622-5

[35] Rurack K 2012 Nanoparticle-based sensors: Striped cation-trappers Nature Materials 11 913-4

[36] Schilardi P L, Dip P, dos Santos Claro P C, Benítez G A, Fonticelli M H, Azzaroni O and Salvarezza R C 2006 Electrochemical Deposition onto Self-Assembled Monolayers: New Insights into Micro- and Nanofabrication Chem. Europ J. 12 38-49

[37] Sevier C S and Kaiser C A 2002 Formation and transfer of disulphide bonds in living cells Nature Reviews Molecular Cell Biology 3 836-47

[38] Smith T 1980 The hydrophilic nature of a clean gold surface Journal of Colloid and Interface Science 75 51-5

[39] Snegir S, Mukha I, Sysoiev D, Lacaze E, Huhn T and Pluchery O 2016 Optically controlled properties of nanoparticles stabilised by photochromic difurylethene-base diarylethenes Materialwissenschaft und Werkstofftechnik 47 229-36

[40] Srisombat L, Jamison A C and Lee T R 2011 Stability: A key issue for self-assembled monolayers on gold as thin-film coatings and nanoparticle protectants Colloids Surf. $A$ $3901-19$

[41] Thome J, Himmelhaus M, Zharnikov M and Grunze M 1998 Increased Lateral Density in Alkanethiolate Films on Gold by Mercury Adsorption Langmuir 14 7435-49

[42] Torres E, Blumenau A T and Biedermann P U 2011 Steric and chain length effects in the ( radical(3) $\times$ radical(3)) $R 30$ degrees structures of alkanethiol self-assembled monolayers on Au(111) Chemphyschem : a European journal of chemical physics and physical chemistry 12 999-1009

[43] Trivedi M V, Laurence J S and Siahaan T J 2009 The role of thiols and disulfides in protein chemical and physical stability Current protein \& peptide science $10614-25$

[44] Ulman A, Kang J F, Shnidman Y, Liao S, Jordan R, Choi G Y, Zaccaro J, Myerson A S, Rafailovich M, Sokolov J and Fleischer C 2000 Self-assembled monolayers of rigid thiols Journal of biotechnology 74 175-88 
[45] Vericat C, Vela M E, Benitez G, Carro P and Salvarezza R C 2010 Self-assembled monolayers of thiols and dithiols on gold: new challenges for a well-known system Chem. Soc. Rev. 39 1805-34

[46] Wang Z J, Chen J H, Oyola-Reynoso S and Thuo M 2016 Empirical Evidence for Roughness-Dependent Limit in Observation of Odd-Even Effect in Wetting Properties of Polar Liquids on n-Alkanethiolate Self-Assembled Monolayers Langmuir 32 8230-7

[47] Witt D 2008 Recent developments in disulfide bond formation Synthesis-Stuttgart 2491509

[48] Yupeng S, Heng Z, Zhenfeng Y, Zhaomin Z, Kar-Seng T, Mei-Jin L, Changqing Y and Mengsu $Y 2013$ Coupling gold nanoparticles to silica nanoparticles through disulfide bonds for glutathione detection Nanotechnology 24375501 